\title{
Phosphocreatine Preconditioning Attenuates Apoptosis in Ischemia-Reperfusion Injury of Rat Brain
}

\author{
Ling-Hua Tang, Zhong-Yuan Xia, Bo Zhao, Xiao-Dong Wei, Tao Luo, and Qing-Tao Meng \\ Department of Anesthesiology, Renmin Hospital of Wuhan University, Wuhan 430060, China \\ Correspondence should be addressed to Zhong-Yuan Xia, xiazhongyuan2005@163.com
}

Received 15 July 2010; Accepted 9 December 2010

Academic Editor: Oreste Gualillo

Copyright () 2011 Ling-Hua Tang et al. This is an open access article distributed under the Creative Commons Attribution License, which permits unrestricted use, distribution, and reproduction in any medium, provided the original work is properly cited.

Phosphocreatine (PCr) is an endogenous compound containing high-energy phosphate bonds. It has been confirmed that PCr is effective in preventing and treating cardiac and renal ischemia-reperfusion injury. In this study, rat cerebral ischemia-reperfusion injury models were constructed. Apoptotic cells in the cortex region were measured by TUNEL method. Malondialdehyde (MDA) content was detected by chromatometry, and calmodulin (CaM) activity was detected by ELISA. Compared with sham-operated group (sham group), TUNEL-positive cells, MDA, and level of CaM activity increased in ischemia-reperfusion group (I/R group) and PCr preconditioning group (PCr group); compared with I/R group, TUNEL-positive cells, MDA content, and level of CaM activity decreased in PCr group. This study indicated that $\mathrm{PCr}$ can decrease the morphological damage and the neuron apoptosis of the ischemia-reperfusion injury brain through attenuating abnormalities of calcium balance and production of oxygen free radicals.

\section{Introduction}

Acute cerebral ischemic reperfusion injury (CIRI), a hotspot for clinical research, is a pathophysiologic phenomenon commonly encountered in the field of emergency medicine, especially during the perioperative periods. The brain can store so little energy reserves that it is highly sensitive to ischemia and hypoxia. Studies have shown that interrupting the cerebral blood flow for $10 \mathrm{~s}$ can lead to loss of consciousness. If cerebral blood flow is blocked for more than $5 \mathrm{~min}$, permanent brain damage is inevitable [1]. Phosphocreatine ( $\mathrm{PCr}$ ) has been used as cardioplegic and cardioprotective agents during cardiopulmonary bypass and also ischemic events [2]. In recent years, some reports showed that $\mathrm{PCr}$ improved the outcome after stroke and neonatal hypoxic ischemic encephalopathy [3]. There have been no studies done to investigate the effect of PCr during acute CIRI. So we designed this research using acute rat CIRI model to observe the effect of $\mathrm{PCr}$ and investigate its possible mechanism.

\section{Materials and Methods}

2.1. Materials. All experimental procedures were done in accordance with the guide for the care and use of laboratory animals. All surgical procedures have been approved by the committee for experimental animals of Centre for Disease Control and Prevention of Hubei Province. 36 male Wistar rats weighing 200 220 g were acquired from the Experimental Animal Center of Hubei Province, Wuhan, China. Sodium creatine phosphate injection was purchased from Haikou Kellett Pharmaceutical Co., China.

2.2. Animal Model and Grouping. 36 Wistar rats were randomly divided into 3 groups: sham-operated group (sham group, $n=12$ ), ischemia-reperfusion group (I/R group, $n=12$ ), $\mathrm{PCr}$ preconditioning group ( $\mathrm{PCr}$ group, $n=12$ ). The rats were anesthetized by $10 \%$ chloral hydrate. CIRI rat models were produced by electrocauterizing bilateral vertebral arteries and occlusion of bilateral common carotid arteries using atraumatic clasps [4]. It was considered a success as the eyeballs turn white and pupils were dilated. The clasps were released $10 \mathrm{~min}$ later and followed by a 48 -hour reperfusion. In sham group, bilateral common carotid arteries were exposed but not clamped. In PCr group, PCr $150 \mathrm{mg} \cdot \mathrm{kg}^{-1}$ was administered intravenously $60 \mathrm{~min}$ before the bilateral common carotid arteries were occluded; normal saline was administered intravenously in $\mathrm{I} / \mathrm{R}$ group simultaneously. 


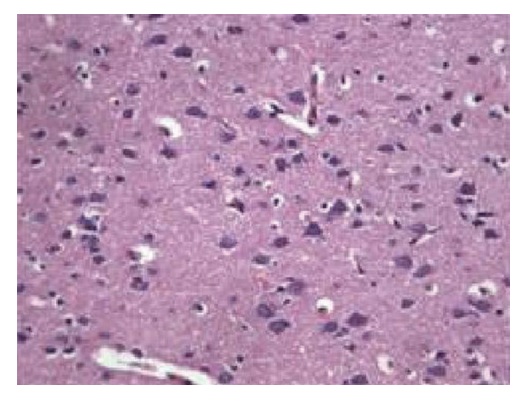

(a)

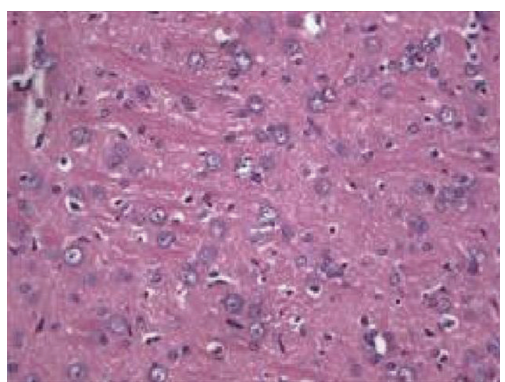

(b)

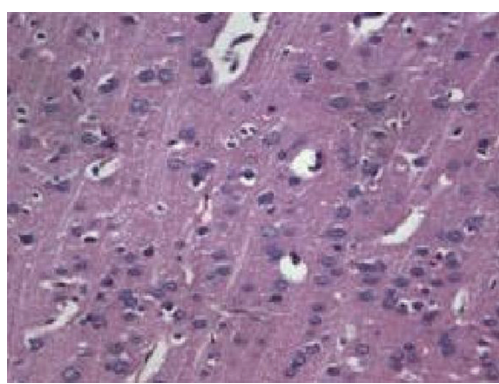

(c)

FIGURE 1: Pathologic changes of brain tissues $(\times 400)$. (a) Sham group; (b) I/R group; (c) PCr group.

Core body temperatures were monitored with a rectal probe and maintained between $36.5^{\circ} \mathrm{C} \sim 37.5^{\circ} \mathrm{C}$ during the whole procedure. 3 rats from I/R group and 1 from PCr group were excluded within $24 \mathrm{~h}$ while the remaining ones were regarded as successful models.

2.3. HE Staining, Light Microscopy. After routine HE staining, pathological changes of the brain tissue were observed under a light microscopy $(\times 400)$.

2.4. TUNEL Staining. The level of cell apoptosis was determined with a Roche in situ cell-apoptosis-assay kit with nuclei stained in brown particles (Shanghai Runwell Technology Co., China). 10 high-power fields $(\times 400)$ were randomly selected, and the number of apoptotic cells was counted for each field.

2.5. Assay of CaM Activity and MDA Content. CaM activity $\left(\mathrm{mmol} \cdot \mathrm{L}^{-1}\right)$ was measured using rat CaM ELISA kit $(\mathrm{R} \& \mathrm{D}$ Company, US); MDA content $\left(\mathrm{nmol} \cdot \mathrm{L}^{-1}\right)$ was detected with MDA kit; protein content $\left(\mathrm{mg} \cdot \mathrm{L}^{-1}\right)$ in corresponding tissue was detected with Coomassie brilliant blue protein assay kit (both from Nanjing Jiancheng Bio Co., China). MDA content in the tissue was calculated using the following formula:

$$
\begin{aligned}
& \operatorname{MDA}\left(\mathrm{nmol} \cdot \operatorname{mgprot}^{-1}\right) \\
& =\frac{\operatorname{MDA} \text { content }\left(\mathrm{nmol} \cdot \mathrm{L}^{-1}\right)}{\text { protein content }\left(\mathrm{mg} \cdot \mathrm{L}^{-1}\right) \text { in corresponding tissue }} \times 5 .
\end{aligned}
$$

2.6. Statistical Analysis. Results were expressed as mean \pm SD. Data were statistically evaluated by one-way ANOVA (SNK) tests and Dunnett's tests, with the level of significance chosen as $P<.05$.

\section{Results}

3.1. Brain Pathologic Changes. In sham group, the cortical neurons are arranged in neat rows with abundant cytoplasm, and the nuclei are round and basophilic. In I/R group, the structures of the cortical neurons are damaged. The cytoplasm is light red with uneven distribution and vacuoles, nuclei are condensed. In PCr group, however, the cell structure is normal. Most of the neurons have complete membrane integrity and the nuclei are clear (Figure 1).

3.2. PCr Preconditioning Reduced Cell Apoptosis. A few TUNEL-positive cells were observed in the cortex of rats in sham group whereas a large number of TUNEL-positive cells was observed in the cortex of rats subject to I/R injury; compared with I/R group, the number of TUNEL positive cells was significantly reduced in the cortex of $\mathrm{PCr}$ group (Figures 2 and 3 ).

3.3. CaM Activity. CaM activity was $4.328 \pm 0.422 \mathrm{mmol} / \mathrm{L}$ in sham group. The CaM activity of I/R group and PCr group was significantly increased at 48 hours after reperfusion compared with sham group whereas CaM activity was significantly decreased in the cortex of PCr group compared with I/R group (Figure 4).

3.4. MDA Content. MDA content was $4.792 \pm 0.451 \mathrm{nmol} /$ mgprot in sham group. MDA in I/R group and PCr group was significantly increased at 48 hours after reperfusion compared with sham group, but compared with I/R group, MDA content was significantly decreased in the cortex of PCr group (Figure 5).

\section{Discussion}

Rapid exhaustion of energy is one of the important etiological factors of ischemia-reperfusion injury $[5,6]$. We hypothesized that supplication of an exogenous energy substrate before ischemic reperfusion might be an important logical therapeutic step. PCr is a very important energy substrate [7], it can go through the blood-brain barrier, even through the cell membrane, to supply energy to cells directly. It possesses 3-times FDP and 1.5-fold of ATP energy level. In this study, we have demonstrated that PCr preconditioning attenuated cell apoptosis and the morphological damage during cerebral ischemia-reperfusion in rats. In ischemiareperfusion injury brain, the apoptotic neurons extensively exist. The cytoplasm is light red with uneven distribution and vacuoles, and nuclei are condensed under light microscopy after reperfusion for $48 \mathrm{~h}$. Compared with I/R group, the 


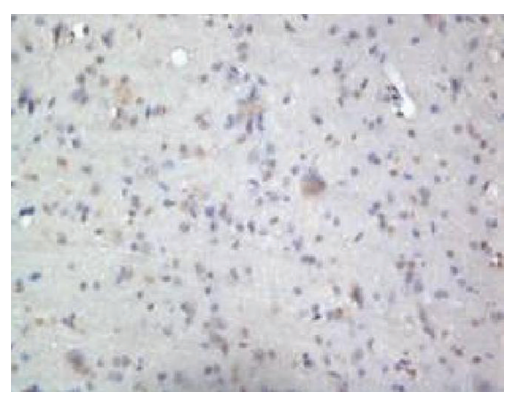

(a)

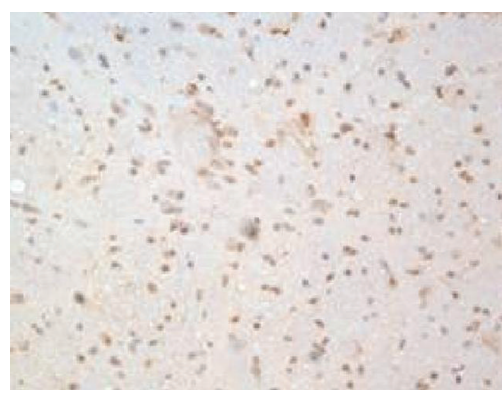

(b)

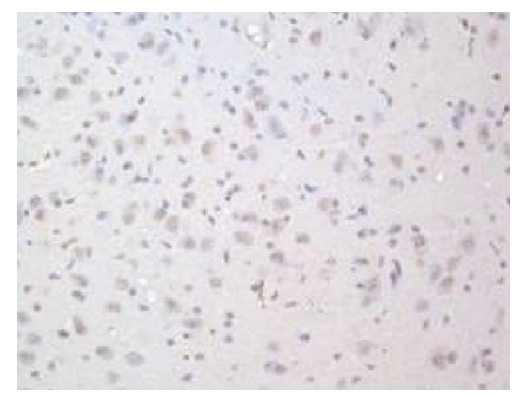

(c)

FIGURE 2: Apoptotic cells in each group (TUNEL $\times 400$ ). (a) Almost no cell is positive for TUNEL in sham group. (b) Many cells are positive for TUNEL in I/R group. Nucleuses that are brownish or dark brown are positive. (c) A few cells are positive for TUNEL in PCr group.

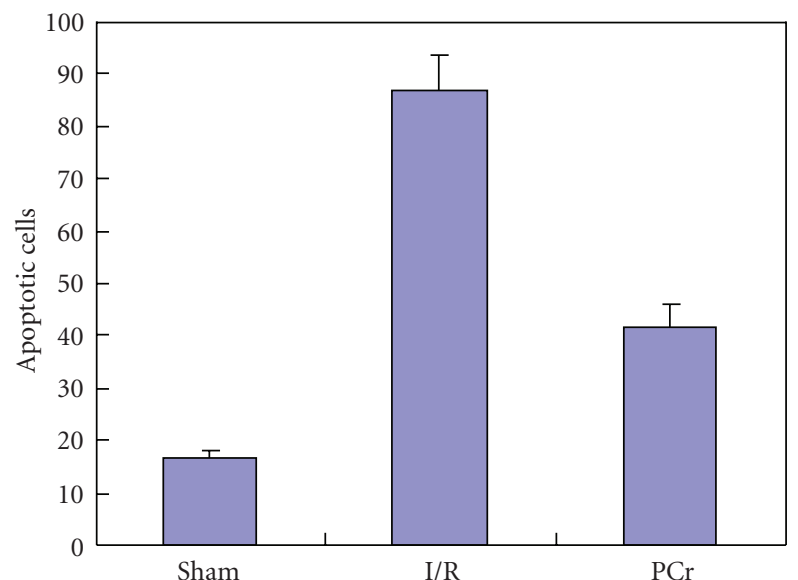

Apoptotic cells

Figure 3: After we deal with the brain slices with an in situ cellapoptosis-assay kit, we counted the number of apoptotic cells in each field.

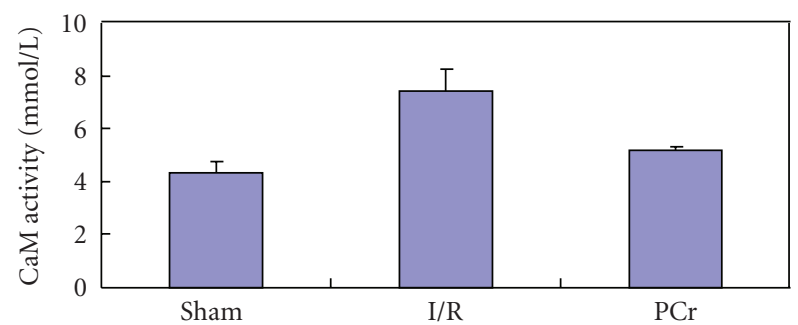

$\mathrm{CaM}$

Figure 4: CaM activity $\left(\mathrm{mmol} \cdot \mathrm{L}^{-1}\right)$ was measured using rat CaM ELISA kit.

number of apoptotic cells was significantly decreased and cerebral ischemia-reperfusion injury was alleviated in $\mathrm{PCr}$ group.

Imbalance of neuronal calcium homeostasis and increase in oxygen free radical are important aggravating factors of cerebral ischemic reperfusion injury [8]. Energy deficiency

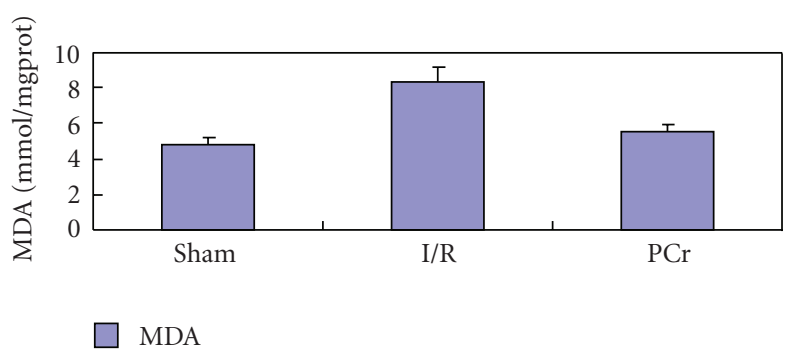

FIGURE 5: MDA content $\left(\mathrm{nmol} \cdot \mathrm{L}^{-1}\right)$ was detected with MDA kit; protein content $\left(\mathrm{mg} \cdot \mathrm{L}^{-1}\right)$ in corresponding tissue was detected with Coomassie brilliant blue protein assay kit. MDA content in the tissue was calculated using the following formula: MDA $\left(\mathrm{nmol} \cdot \mathrm{mgprot}^{-1}\right)=\mathrm{MDA}$ content $\left(\mathrm{nmol} \cdot \mathrm{L}^{-1}\right) /$ protein content $\left(\mathrm{mg} \cdot \mathrm{L}^{-1}\right)$ in corresponding tissue $\times 5$.

causes intracellular calcium overload and an increase in oxygen free radical. To assess the intracellular $\mathrm{Ca}^{2+}$ overload and oxygen free radical level, CaM activity and cerebral MDA content were determined. CaM is a calcium-binding protein. It combines with $\mathrm{Ca}^{2+}$ reversibly, and regulates transmembrane calcium transportation, absorption, and secretion. An increase in activity of CaM means an elevation of intracellular ionized $\mathrm{Ca}^{2+}$ concentration, hence causing calcium imbalance in the cells [9]. MDA is a stable lipid peroxide end product produced during the oxidation of membrane lipid unsaturated fatty acid by oxygen free radical. The central nervous system is rich in unsaturated fatty acids that interact with oxygen free radical during reperfusion after an ischemic event, which generates a large amount of MDA. Therefore, MDA level indirectly reflects the level of oxygen free radical and the degree of lipid peroxidation in the brain tissue.

We found that the CaM activity was elevated in I/R group compared with sham group, indicating the increase of $\mathrm{Ca}^{2+}$ influx, $\mathrm{Ca}^{2+}$ overload, and $\mathrm{Ca}^{2+}$ balance disturbance. The high MDA content in $\mathrm{I} / \mathrm{R}$ group suggested that oxidative stress occurred and a large amount of lipid peroxide was produced. PCr group demonstrated a significantly lower $\mathrm{CaM}$ activity. Thus, there were lower incidences of $\mathrm{Ca}^{2+}$ reflux, $\mathrm{Ca}^{2+}$ overload, and complex pathological changes induced by $\mathrm{Ca}^{2+}$ overload. PCr group also had lower MDA level, indicating that PCr induced a significant suppression in 
the generation of free radical and provided an antioxidative protection to the cell and organelle membranes, hence attenuating cellular necrosis and apoptosis.

During ischemia-reperfusion, $\mathrm{Ca}^{2+}$ overload leads to mitochondrial dysfunction, and oxygen free radical increases [10]. We have found that PCr preconditioning decreases CaM activity, thus preventing calcium overload, reducing the production of oxygen free radical indirectly. As an ATP precursor, PCr releases high-energy phosphate bond to synthesize ATP, supplying neurons with energy, reducing the production of lactic acid, and maintaining the function of $\mathrm{Na}^{+}-\mathrm{Ca}^{2+}$ exchange [3]. It is suggested that $\mathrm{PCr}$ preconditioning ensures sufficient ATP supply, keeps $\mathrm{Ca}^{2+}$ pump working, and sustains $\mathrm{Ca}^{2+}$ balance [11]. It can also inhibit the formation of Hypoxanthine, thereby reducing the production of oxygen free radicals [12].

Currently, the methods of preconditioning include mechanical preconditioning and pharmacologic preconditioning. The drawback of clinical application of mechanical preconditioning is the difficulty in predicting the onset of any ischemic event. Even if it's predictable, the application of a transient mechanical preconditioning is impractical before cerebral ischemia. Therefore, the clinical application of mechanical preconditioning was limited.

One of the important etiological factors of ischemiareperfusion injury is due to the rapid exhaustion of energy $[5,6]$. Therefore, a supply of an exogenous energy substance during ischemic reperfusion may be an important logical therapeutic step. Phosphocreatine (PCr) is an endogenous compound containing high-energy phosphate bonds. It acts as an energy reserve, and it is mainly synthesized by the kidneys. The finding of the current study provides a promising method for the treatment of cerebral ischemiareperfusion injury. However, only brain pathological and apoptotic changes were investigated in the current study. Future study will be needed to further evaluate the effect of PCr on brain infarct size, neurological score and so forth. The assessment of functional and histological endpoints as well as multiple neurological outcomes will allow better understanding of the PCr's role in brain ischemia.

\section{Conclusion}

In summary, we demonstrated the protective effect of $\mathrm{PCr}$ during cerebral ischemic reperfusion injury. Based on the pharmacokinetic characteristics of $\mathrm{PCr}$, we speculate that $\mathrm{PCr}$ should be administered preoperatively to hemodynamic unstable patients, such as aortic aneurysm surgical patients, who may develop cerebral ischemia during surgery when the major arteries are clamped. Other patients with severe head injury, hemorrhagic shock, cerebral vasospasm, and respiratory and cardiac arrest may also benefit from the protection against cerebral ischemic reperfusion injury.

\section{Acknowledgment}

This work was sponsored by the National Nature Science Foundation of China (Grant no. 30672033).

\section{References}

[1] T. Yao and Z. Q. Ruo, Physiology, vol. 177, People's Health Press, 1st edition, 2005.

[2] D. J. Chambers, K. Haire, N. Morley et al., "St. Thomas' hospital cardioplegia: enhanced protection with exogenous creatine phosphate," Annals of Thoracic Surgery, vol. 61, no. 1, pp. 67-75, 1996.

[3] M. Balestrino, M. Lensman, M. Parodi et al., "Role of creatine and phosphocreatine in neuronal protection from anoxic and ischemic damage," Amino Acids, vol. 23, no. 1-3, pp. 221-229, 2002.

[4] W. A. Pulsinelli and J. B. Brierley, "A new model of bilateral hemispheric ischemia in the unanesthetized rat," Stroke, vol. 10, no. 3, pp. 267-272, 1979.

[5] M. Parodi, R. Rebaudo, L. Perasso, C. Gandolfo, A. Cupello, and M. Balestrino, "Effects of exogenous creatine on population spike amplitude and on postanoxic hyperexcitability in brain slices," Brain Research, vol. 963, no. 1-2, pp. 197-202, 2003.

[6] A. Ames III, "CNS energy metabolism as related to function," Brain Research Reviews, vol. 34, no. 1-2, pp. 42-68, 2000.

[7] G. Prabhakar, L. Vona-Davis, D. Murray, P. Lakhani, and G. Murray, "Phosphocreatine restores high-energy phosphates in ischemic myocardium: implication for off-pump cardiac revascularization," Journal of the American College of Surgeons, vol. 197, no. 5, pp. 786-791, 2003.

[8] Y. Shirasaki, Y. Kanazawa, Y. Morishima et al., "Involvement o f calmodulin in neuronal cell death," Brain Research, vol. 1083, no. 1 , article 189, 2006.

[9] T. Sato, H. Takamori, and Y. Shirasaki, "DY-9760e, a novel calmodulin antagonist, reduces infarction after permanent focal cerebral ischemia in rats," Pharmacology, vol. 71, no. 1, pp. 38-45, 2004.

[10] S. Yano, M. Morioka, J.-I. Kuratsu, and K. Fukunaga, "Functional proteins involved in regulation of intracellular $\mathrm{Ca}^{2+}$ for drug development: role of calcium/calmodulin-dependent protein kinases in ischemic neuronal death," Journal of Pharmacological Sciences, vol. 97, no. 3, pp. 351-354, 2005.

[11] Z.-C. Feng, T. J. Sick, and M. Rosenthal, "Oxygen sensitivity of mitochondrial redox status and evoked potential recovery early during reperfusion in post-ischemic rat brain," Resuscitation, vol. 37, no. 1, pp. 33-41, 1998.

[12] F. Zhang, Z. Xu, J. Gao, B. Xu, and Y. Deng, "In vitro effect of manganese chloride exposure on energy metabolism and oxidative damage of mitochondria isolated from rat brain," Environmental Toxicology and Pharmacology, vol. 26, no. 2, pp. 232-236, 2008. 


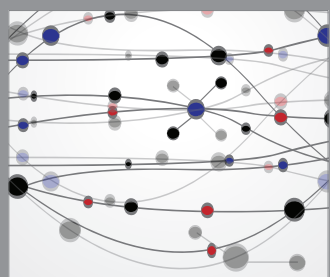

The Scientific World Journal
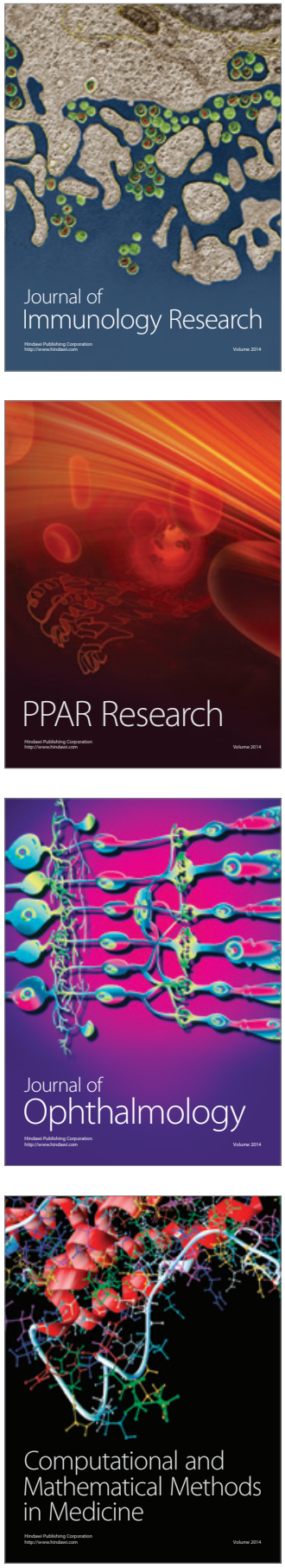

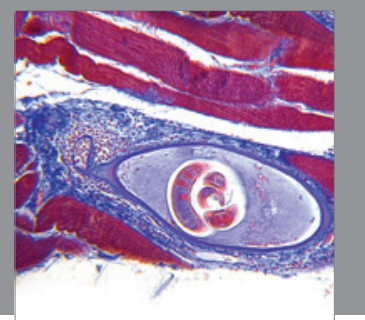

Gastroenterology

Research and Practice
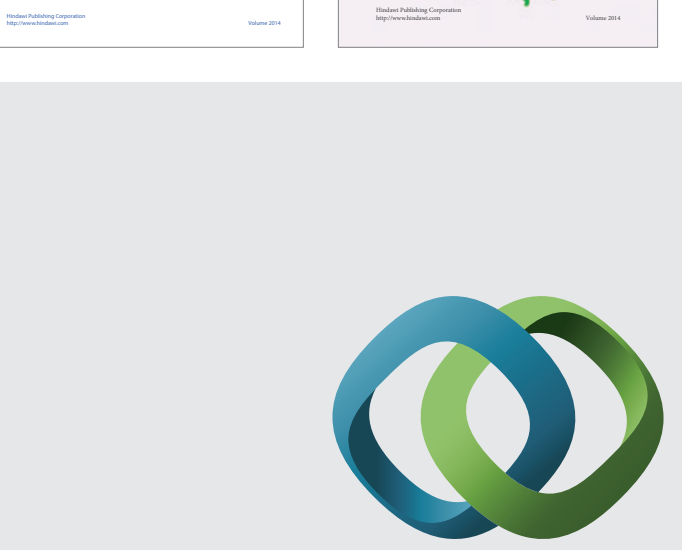

\section{Hindawi}

Submit your manuscripts at

http://www.hindawi.com
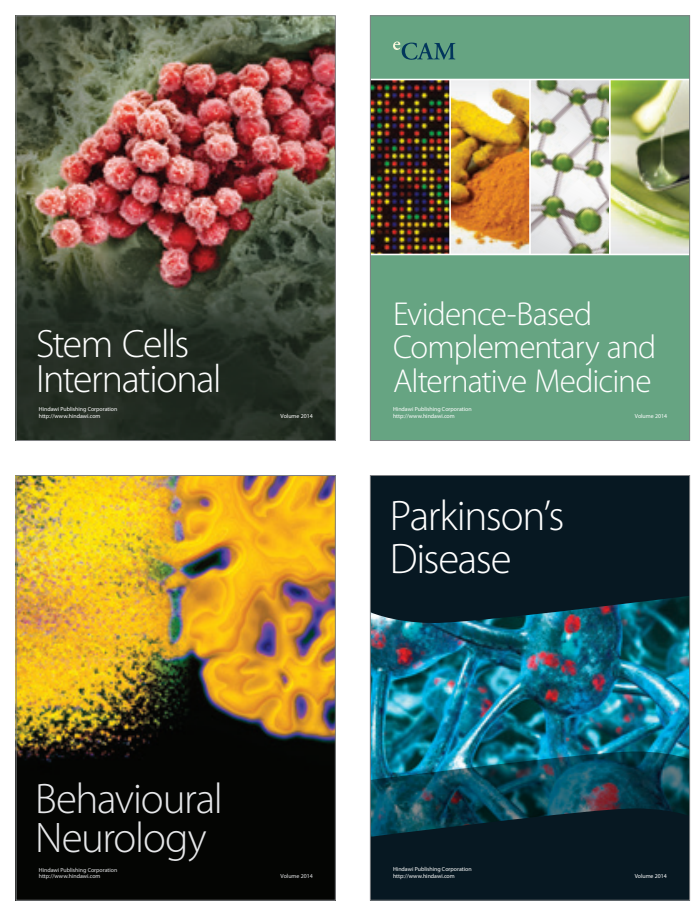

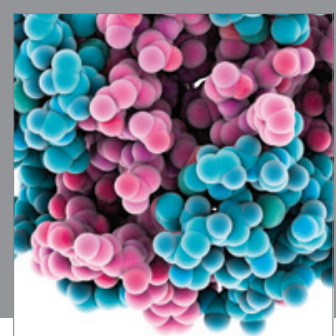

Journal of
Diabetes Research

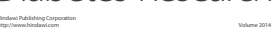

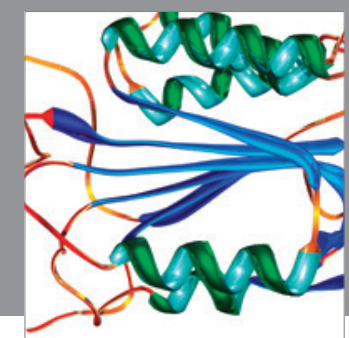

Disease Markers
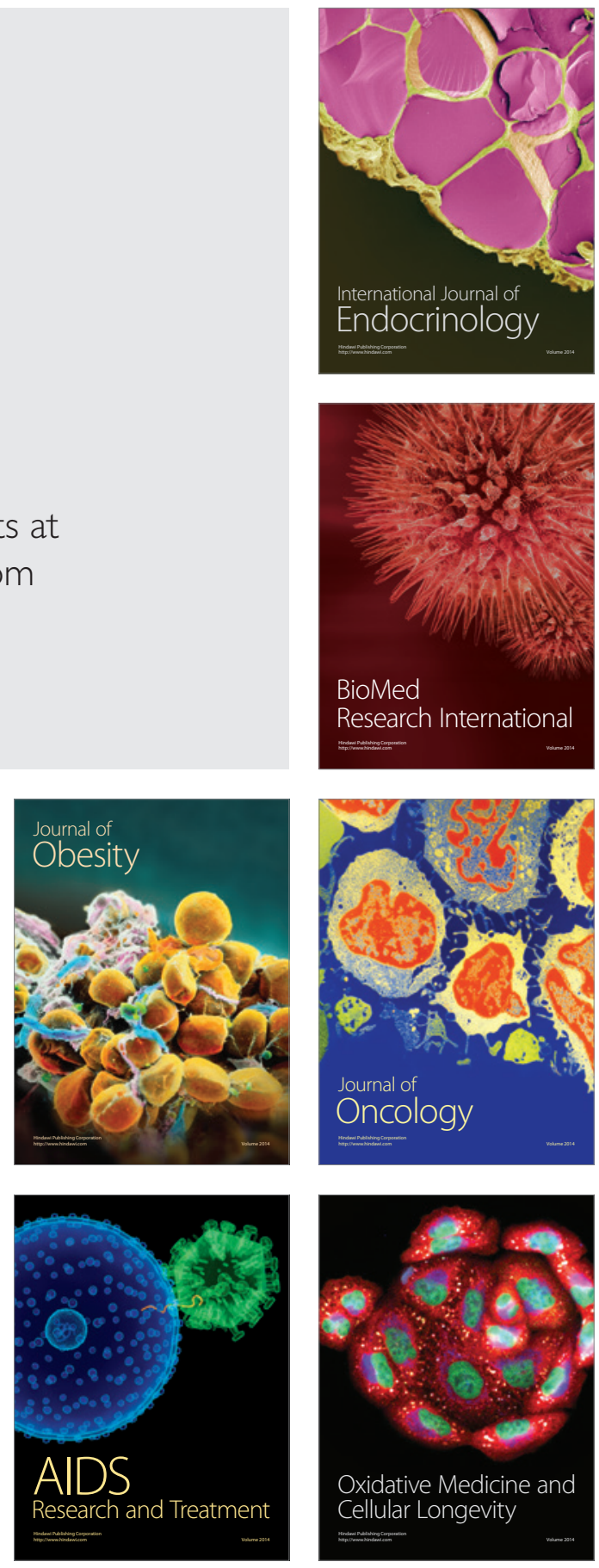